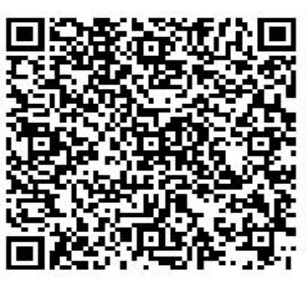

\title{
RELATIONSHIP BETWEEN IRRATIONAL BELIEFS AND DEPRESSION IN LATE ADOLESCENCE
}

\author{
Elizabeth Jasmine* \& G. Venkatesh Kumar**
}

\begin{abstract}
The present study was aimed at examining the relationship between Irrational Beliefs and Depression among the late adolescent college students $(N=502)$. Studies have found depression to be one of the most crippling disorders and the leading cause for suicide among all age groups and that this state is primarily being caused by wrong thinking and belief patterns such as irrational beliefs and further irrational beliefs are being maintained due to the depressed state of the individual. Hence the present study apart from analyzing the directions of possible relationship of Irrational Beliefs with Depression, reviews the existing literature to showcase how one causes and maintains the other.
\end{abstract}

\section{Introduction}

In children and adolescents, irrational thinking is conceptualized in cognitive models as being a normal part of the developmental process. In early childhood, irrational

* Research Scholar, Dept. of Psychology, University of Mysore.

** Dept. of Psychology, University of Mysore, Manasagangothri, Mysore. 
thoughts are developmentally appropriate. Gradually, with time, they decrease, giving way to rational thinking processes during adolescence (Angold, A., 1988). Therefore, it can be said that in general, children give up most of their irrational ideas when they grow up, and that psychopathology develops when there is a failure to abandon the immature thinking process. In other words, problems develop when age-inappropriate thinking is present. More specifically with adolescents, it is possible to expect that cognitive dysfunctional processes would be influenced by the maturational thinking process of formal thinking, which is hypothesized to be consolidated during the middle of adolescence (Piaget, 1972).

Cognitive theorists have explained the etiology of depression repeatedly based on various studies (Beck, 1967, 1976; Rush, Shaw, \& Emery, 1979; Ellis, 1962; Lewinsohn, 1977). In Beck's cognitive therapy, depressive disorder is explained in terms of 'depressogenic thinking schemas' related to the self, the future, and the world. This depressed individual's negative view is called "the cognitive triad."

The rational-emotive therapy (RET) model (Ellis \& Grieger, 1977) also focuses on cognitive mediation of 'Irrational Beliefs' as an explanation of emotional disorders. Although not developed specifically for application with depression, RET has shown to be an effective treatment strategy (Horton \& Johnson, 1980; Kujoth \& Topetzes, 1977; Lipsky, Kassinove, \& Miller, 1980; Marcotte \& Baron, 1993). The ABC model of RET suggests that $C$, the emotional consequence of $A$, the event, is mediated by the person's thinking, B. In its view of depression, RET suggests that depressive symptoms are initiated by two types of events that can be related to loss or rejection. Irrational or non-empirical interpretation of these events perpetuates the depressive state (Walen, DiGuiseppe, \& Wessler, 1980).

Four categories of irrational beliefs that distort the cognitions are defined by Ellis, representing thinking modes which are non-empirical and reflect an absolutistic view of reality. These cognitive distortions are: (1) awfulizing beliefs ("some situations in life are horrible"); (2) low frustration tolerance cognitions ("I can't stand some things in others"); (3) absolute demands directed at self ("I should succeed totally in everything I decide to do") and at others ("my friends and my family should absolutely treat me better than they sometimes do"); and (4) self-worth beliefs-a person's tendency to globally evaluate himself or herself on the basis of only specific behaviors or characteristics ("a person who makes mistakes or hurts other people is very often a 'bad person") (Demaria, Kassinove, \& Dill, 1989). 


\section{Methodology:}

Objective of the study: To study the relationship between irrational beliefs, and depression in causing each other during late adolescence

\section{Tools Used}

1. The Beck Depression Inventory (BDI) (Beck, 1978; Beck \& Beamesderfer, 1974; Beck, Ward, Mendelsohn, Mock, \& Erbaugh, 1961; Bourque \& Beaudette, 1982 ) is a well-known self-report measure of depression. The BDI includes 21 items assessing the severity of affective, behavioral, cognitive, and somatic symptoms of depression. For each item, a choice is made between four statements graduated from 0 to 3; global scores range from 0 to 63. Norms of 0 to 9 (absence), 10 to 15 (mild), 16 to 23 (moderate), and 24 and above (severe) were suggested by Burns and Beck (1978). Psychometric properties of the BDI have been confirmed for use with adolescents (Teri, 1982; Strober, Green, \& Carlson, 1981 ; Barrera \& Garrison-Jones, 1988). An internal stability coefficient of .87 and correlation coefficients item-total of .27 to .62 were found (Teri, 1982). Barrera and Garrison-Jones (1988) also confirmed convergent and discriminant validity of the BDI with adolescents.

2. The Irrational Beliefs Scale (IBS): The presence of Irrational Beliefs was assessed using a 50 item investigator developed irrational belief's scale. It is a brief version of the Irrational Beliefs Test developed by Jones (1968). It is a selfreport measure of irrational thinking constructed in accordance with the rational-emotive model. It provides information on a global score of irrationality. The IBS includes 50 items within ten categories. Subjects rate their responses on a five-point Likert scale $(5=$ totally agree to $1=$ totally disagree). An elevated score on the IBS indicates high level of irrational beliefs. The standardization sample involved 445 late-adolescent subjects, aged between 18-22years. The Scale was found to have a Cronbach's Alpha Coefficient of 0.83 . Reliability by Split-Half method-correlation between forms is 0.68 ; Equal Length Spearman- Brown Coefficient is 0.65; Unequal Length Spearman Brown Coefficient is 0.65 ; Cronbach's Alpha for part I is 0.74 and that for part 11 is 0.78 . The instrument has good content validity and face validity.

3. Demographic Questionnaire: An investigator-developed demographic details questionnaire was used to solicit demographic information, such as participants' age, gender socioeconomic status, and educational level, family background etc. 
Sample: The subjects chosen for the study were 502 undergraduate students between the age groups of $17-23$ studying in various undergraduate courses of Christ College, one of the undergraduate colleges in the city of Bangalore. Most of the subjects were belonging to urban backgrounds and a few were from rural backgrounds, however all of them were from economically privileged families. All the subjects were residents of Bangalore during the course of the study with some being permanent and others, temporary residents. All the participants of the study were fluent in spoken and written English which helped the researcher during the course of the study.

\section{Procedure}

The Beck Depression Inventory (BDI) and Irrational Beliefs Scale (IBS) along with the demographic questionnaire were administered to various group of late adolescent college students. The responses were scored and interpreted. Adequate rapport was established and confidentiality of results was assured to the subjects of the study. Pearson's Product Moment method was used to find the correlation coefficient between the scores on BDI and IBS.

\section{Results and Discussion}

Positive correlations were found between Irrational Beliefs, measured by the Irrational Beliefs scale (IBS), and the presence of depressive symptoms, reported on Beck's depression Inventory (BDI) $(r=0.406, \mathrm{P}<.001)$ Strength of relationship between the two sets of score was found be very high as indicated by the r value found using Pearson's Product Moment method. Thus the global score on the IBS was correlated highly with the score on BDI. The obtained ' $r$ ' value indicates that as irrational beliefs increased, reported depressive symptoms also increased and vice versa.

Results of this study support the hypothesis regarding the co-occurrence of depressive symptoms and irrational beliefs, and highlight the presence of a relationship between cognitive distortions and depression in adolescence observed in previous studies (Marton et al., 1993; Dalley et al., 1992)

Studies have indicated that, with age, adolescents are less likely to adopt a cognitive bias linked to a low frustration tolerance, but tend to adopt more unrealistic demands toward themselves. High-depressive and low-depressive adolescents presented different levels of irrational beliefs related to 'awfulizing beliefs', 'low frustration tolerance', and 'self-directed-shoulds' in addition to different global scores of irrationality. In a study of the efficacy of a cognitive intervention to treat adolescent 
depression (Marcotte \& Baron, 1993) it was found that irrational beliefs linked to 'low frustration tolerance' and 'awfulizing' were two of the three kinds of cognitive biases which showed the most improvement by the end of the treatment, the other one being 'self-value beliefs'.

On the other hand, the tendency of adolescents to become focused on themselves and to fail to adopt others' perspectives, called adolescent egocentrism (Elkind, 1967), is reflected in the increase of irrational beliefs related to absolute demands directed toward themselves. This suggests that adolescents could become more vulnerable to depression because of this tendency and could adopt self-value criteria about their physical appearance or social characteristics that are impossible to reach and would result in feelings of depression. As Young (1983) highlighted, adolescents tend to exaggerate and interpret reality in a wrong way, to transform wishes into necessities, and to view weakness as a proof of their personal incompetence.

Results of empirical studies with adults, both in the Beck cognitive model of depression (Dobson \& Shaw, 1986; Eaves \& Rush, 1984), and in the rational-emotive model (Muran, Kassinove, Ross, \& Muran, 1989; Newmark \& Ziff, 1977) have confirmed the co-occurence of cognitive distortions and depressive symptoms. The existence of these thinking patterns in depressed young people has been confirmed with the present study. In conclusion, the present study supported the existence of a very clear positive relationship between irrational beliefs and depression among late adolescents.

\section{References}

Angold, A. (1988). Childhood and adolescent depression: 1. Epidemiological and aetiological aspects. British Journal of Psychiatry, 152, 601-617.

Barrera, M., \& Garrison-Jones, C. V. (1988). Properties of the Beck Depression Inventory as a screening instrument for adolescent depression. Journal of Abnormal Child Psychology, 16, 263-273.

Beck, A. T. (1967). Depression: Clinical, experimental, and theoretical aspects. New York: Hoeber.

Beck, A. T. (1976). Cognitive therapy and the emotional disorders. Madison, NJ: International Universities Press.

Beck, A. T. (1978). Depression inventory. Philadelphia, PA: Center for Cognitive Therapy.

Beck, A. T., \& Beamesderfer, A. (1974). Psychological measurements in psychopharmacology. In P. Pichot (Ed.), Modern problems in psychopsychiatry (Nol. 7). Basel, Switzerland: Karger.

Beck, A. T., Rush, A. J., Shaw, B. F., \& Emery, G. (1979). Cognitive therapy of depression. New York: Guilford Press. 
Beck, A. T., Ward, Co H., Mendelson, M., Mock, J., \& Erbaugh, J. (1961). An inventory for measuring depression. Archives of General Psychiatry, 4, 561-571.

Bourque, P., \& Beaudette, D. (1982). Etude psychometrique du questionnaire de depression de Beck aupres d'un echantillion d'etudiants universitaires francophones. Revue Canadienne des Sciences du Comportement, 14(3), 211-18.

Burns, D., \& Beck, A. T. (1978). Cognitive behavior modification of mood disorders. In J. P. Foreyt, \& D. Rathien (Eds.), Cognitive behavior therapy: Research and applications. New York: Plenum Press.

Dalley, M. B., Bolocofsky, D. N., Alcorn, M. B., \& Baker, C. (1992). Depressive symptomatology, attributional style, dysfunctional attitude, and social competency in adolescents with and without learning disabilities. School Psychology Review, $21(3), 444-458$.

Demaria, T. P., Kassinove, H., \& Dill, C.A. (1989). Psychometric properties of the Survey of Personal Beliefs: A rational-emotive measure of irrational thinking. Journal of Personality Assessment, 52(2), 329-341.

Dobson, K. S., \& Shaw, B. F. (1986). Cognitive assessment with major depressive disorders. Cognitive Therapy and Research, 10, 13-29.

Eaves, G., \& Rush, A. J. (1984). Cognitive patterns in symptomatic and remitted unipolar major depression. Journal of Abnormal Psychology, 93, 31-40.

Elkind, D. (1967). Egocentrism in adolescence. Child Development, 38(9), 1025-1034.

Ellis, A. (1962. Reason and emotion in psychotherapy. Secaucus, NJ: Citadel.

Ellis, A., \& Grieger, R. (1977). Handbook of rational-emotive therapy. New York: Springer Pub. Co.

Garber, J., Weiss, B., \& Shanley, N. (1993). Cognitions, depressive symptoms, and development in adolescents. Journal of Abnormal Psychology, 102(1), 47-57.

Harrington, R., Fudge, H. Rutter, M., Pickles, A., \& Hill, J. (1990). Adult outcomes of childhood and adolescent depression. Archives of General Psychiatry, 47, 465-473.

Horton, A., \& Johnson, C. H. (1980). Rational-Emotive therapy and depression: A clinical study. Perceptual and Motor Skill, 51, 853-854.

Kauth, M. R., \& Zettle, R. D. (1990). Validation of depression measures in adolescent populations. Journal of Clinical Psychology, 46(3), 291-295.

Kujoth, R. K., \& Topetzes, N. J. (1977). A rational-emotive approach to mental health for college students: Study I. College Student Journal, 11, 1-6.

Lewinsohn, P. M. (1977). The behavioral study and treatment of depression. In M. Hersen, R. M. Eisler, \& P. M. Miller (Eds.), Progress in behavior modification. New York: Academic Press.

Lipsky, M. J., Kassinove, H., \& Miller, N. J. (1980). Effects of rational-emotive therapy, rational role reversal, and rational-emotive imagery on the emotional adjustment of community mental health center patients. Journal of consulting and Clinical Psychology, 48, 366-374.

Marcotte, D., \& Baron, P. (1993). L'efficacite d'une strategie d'intervention emotivo-rationnelle aupres d'adolescents depressifs du milieu scolaire. Canadian Journal of Counselling, 27(2), 77-92. 
Marcotte, Diane, Adolescence, adolescence magazine, (1996)

Marton, P., Churchard, M., \& Kutcher, S. (1993). Cognitive distortion in depressed adolescents. Journal of Psychiatry and Neurosciences, 18(3), 103-107.

Marton, P., Connolly, J., Kutcher, S., \& Korenblum, M. (1993). Cognitive social skills and social self-appraisal in depressed adolescents. Journal of American Academy of Child and Adolescent Psychiatry, 32(4), 739-744.

Muran, J. C., Kassinove, H., Ross, S., \& Muran, E. (1989). Irrational thinking and negative emotionality in college students and applicants for mental health services. Journal of Clinical Psychology, 45(2), 188-193.

Newmark, C., \& Ziff, D. R. (1977). Ellis irrational beliefs: Congruity between patients' endorsement and psychologists' predictions. Professional Psychology, 8(2), 48-55.

Nolen-Hoeksema, S. (1990). Sex difference in depression. Standford, CA: Standford University Press.

Piaget, J. (1972). Intellectual evolution from adolescence to adulthood. Human Development, $15,1-12$.

Rutter, M. (1991). Age changes in depressive disorders: Some developmental considerations. In J. Garber, \& K. A. Dodge (Eds.), The development of affect regulation and dysregulation. New York: Cambridge University Press.

Strober, M., Green, J., \& Carlson, G. (1981). Utility of the Beck Depression Inventory with psychiatrically hospitalized adolescents. Journal of Consulting and Clinical Psychology, $49(3), 482-483$.

Teri, L. (1982). The use of the Beck Depression Inventory with adolescents. Journal of Abnormal Child Psychology, 10, 277-284.

Walen, S. R., Diguiseppe, R., \& Wessler, R. L. (1980). A practitioner's guide to rational-emotive therapy. New York: Oxford University Press.

Young, H. S. (1983). Principles of assessment and methods of treatment with adolescents. In A. Ellis, \& M. E. Bernard (Eds.), Rational-Emotive approaches to the problems of childhood. New York: Plenum Press. 